\title{
1 \\ Advancing Multicultural Arts: Policies, Problems and Practice
}

The global reality is one in which shifting identities, mass migration and refugee movements are the norm. Since World War II, about 7 million immigrants from over 150 countries have settled in Australia, resulting in a linguistic and cultural diversity that is among the highest in the developed world, and this population trend looks set to continue. There are over 300 languages spoken in Australia with more than one-fifth (21 per cent) of the population speaking a language other than English at home (ABS 2017). It is estimated that 32 per cent of Australians are now from non-Anglo Celtic backgrounds (Soutphommasane 2016).

Policies of multiculturalism were developed in response to rapid demographic changes in Australia's population and have been distinguished by three distinct approaches (Ho 2013,31). The social justice approach focuses on the disadvantages experienced by migrants whose first language was not English; it saw, among other things, the establishment of migrant resource centres and the Special Broadcasting Service (SBS) as the multilingual broadcaster. The productive diversity approach promotes the value of a culturally diverse workforce, such as language skills, intercultural and cross-cultural communication competencies, access to international markets and business knowledge (Ho 2013, 36). Social cohesion promotes the concept of a 'mainstream'-an undefined concept of what it means to be Australian and to which migrants are 
supposed to aspire (Ho 2013, 38). A detailed account of the development of government policies of multiculturalism can be found in work by van Teeseling (2011).

The policies of multiculturalism underscore the tensions that are held in play between plurality and cohesion, the economic advantages afforded by migrants and the cultural aspects of citizenship. These issues regarding multicultural Australia remain topical and contested and, arguably, are among the most important issues to resolve in the context of global migrations. Australian Human Rights Commissioner Dr Tim Soutphommasane (2017) sees the arts as crucial to contributing to conversations about issues of identity and belonging:

It goes to the mission of the arts when they flourish: to nurture creativity, to foster exchange, to encourage understanding and respect. For those of you working for diversity in the arts, this task has become more urgent than ever.

Australia's multicultural society carries with it the potential to create genuinely dynamic arts and cultural spaces in which artists may explore some of the consequences, and offer opportunities to increase understandings, of multiculturalism in action. This chapter presents an historical and sociological overview of multicultural Australia and the artistic expression that arises from this cultural diversity.

The diversity of Australia's population includes a wide range of artistic traditions. Yet, there is a disparity between the socio-demographic aspects of multicultural Australia and cultural and artistic participation. Despite decades of policy directed towards increasing cultural participation, the diversity of the Australian population is not reflected in the country's cultural production (Screen Australia 2016; Australia Council 2014a; Khan et al. 2017, 1). Consequently, there exists enormous potential for artistic gestures and symbols to be explored:

A diversity of cultural expressions is intrinsic to social experience in all contemporary societies. Cultural difference is not something 'out there', outside of us, but part of who we are, irrespective of our cultural or ancestral background. Artistic work can express this intrinsic diversity by mobilising the unpredictable interfaces of intercultural exchange, which can be found everywhere. (Mar and Ang 2015, 8) 
Artists thrive on working with unpredictability and many non-English speaking background (NESB) artists take up the potential offered through intercultural exchange as a point of departure in their creative process. The issue is whether these artists experience adequate support to be able take up the challenges and opportunities presented through a multicultural Australia. This chapter presents demographic data about, and some approaches to, the experiences of Australians living in a multicultural Australia, as well as several arts policy responses. A consideration of those of Arts Council England (ACE) - the organisational body on which the Australia Council for the Arts was modelled-provides an international perspective alongside those of the Canada Council for the Arts (CCA), whose history of colonisation and multiculturalism is similar to Australia's. Australia's national makeup includes six states and two territories, of which arts strategies from four states will briefly be touched upon. A discussion of creativity and types of multicultural arts practices brings the focus to artists.

\section{Multiculturalism as a Social and Cultural Issue}

\section{Multicultural Australia}

According to the 2016 Census, 49 per cent of Australians were either born overseas (first generation of migrants) or have either one or both parents born overseas (the second generation) (ABS 2017). The countries of origin of recent arrivals are changing. There has been a decline in migration from longstanding source countries such as the UK (3.9 per cent as a proportion of total population). In 2017, 2.2 per cent of the Australian population was born in China and 1.9 per cent was born in India (ABS 2017).

The degree of demographic diversity varies significantly across Australian locations. The five mainland state capitals' average populations include 34 per cent of Australians born overseas, as compared to 12 per cent in rural areas. At the suburban level, the data are more dramatic: 88 per cent were born overseas in Haymarket at the southern end of the Sydney central business district in NSW, with the majority born in China, Indonesia and Thailand. In Harris Farm near Parramatta, NSW, 77 per cent were born overseas, mainly (46 per cent) in India. In Clayton, an outer suburb 
of Melbourne, Victoria, 77 per cent were born overseas and are mainly students from China, India and Malaysia (ABS 2013). Australians' social and cultural experiences of multiculturalism through diversity and migration, therefore, are varied and characterised by dynamic change.

Language and national origin form part of the portrait of Australia's demographic diversity. The dynamics of Australian society are made up of multiple intersecting identities that incorporate any combination of race, ethnicity, class and geographic demography. Shifting enthusiasms and increasing scepticism about the value and success of multiculturalism make negotiations of identity particularly complex and ambiguous for NESB artists. Part of this ambivalence is because Australia is no longer made up of discrete ethnic groups that can be readily identified and essentialised and thus more easily represented (Ang 2011, 24; Vertovec 2010, 94).

The evolution of Australia's diverse makeup is caused by widescale immigration, which is now in greater numbers than following World War II. This leads to what Vertovec $(2010,94)$ calls 'super-diversity', whereby migrants and their families possess a 'plurality of affiliations'. Such 'post-multicultural' (Vertovec 2010, 94) discourse suggests that ethnicity is no longer the single most important marker of identity. Noble $(2009,45)$ argues that Australia is 'hyper-diverse', characterised by the development of 'poly-ethnic neighbourhoods', which result in relations and interactions that produce 'a diversification of this diversity'. The ways in which Australians work at engaging with this level of diversity in their daily lives produce different types of experiences of cultural diversitywhich everyone experiences and produces differently. Noble $(2009,51)$ makes the point that this is work: unpaid work that requires 'sustained practices of accommodation and negotiation' to produce conviviality. Art is also work, and is similarly rarely recognised as such (Gerber 2017). In particular, the role of the artist in delivering different ways to approach cultural difference carries those practices of accommodation and negotiation to a wider sphere.

Research into Australian responses to multiculturalism and cultural diversity over the past decade affirm support for migration into Australia. A study undertaken in 2002 found that only about 10 per cent of Australians had a negative view of multiculturalism and cultural diversity (Ang et al. 2002, 5). These findings are challenged by more recent data in the Scanlon Foundation's social cohesion report, completed in 2017. Over the course of the 10-year project, Australians expressed their 
overwhelming acceptance of multiculturalism, although there has been a recent decline. In 2017, 75 per cent of Australians either agreed or strongly agreed that multiculturalism had been good for Australia, whereas that agreement had previously been consistent across the 83-86 per cent range (Markus 2017, 1). This drop was buffered by the positive response from 94 per cent of younger Australians aged between 18 and 24 (Markus 2017,72 ). The decline, however, is reinforced by the doubled increase of those who 'reported experience of discrimination "because of your skin colour, ethnic origin or religion"' from 9 per cent in 2007 to 20 per cent in 2017 (Markus 2017, 3). These figures suggest a chafing between the experiences of the population and the ability to accommodate changes in society. Markus $(2017,3)$ posits that this indicates that, in 2017, Australia was 'less resilient than the Australia of 10 years earlier, less able to deal with economic and other crises that may eventuate in coming years'.

Markus's findings improve upon, but are not dissimilar to, those generated by SBS at the beginning of the century. In 2001 SBS commissioned research to assist them in formulating their future directions. This found that:
The overall picture is one of a fluid, plural and complex society, with a majority of the population positively accepting of the cultural diversity that is an increasingly routine part of Australian life, although a third is still uncertain or ambivalent about cultural diversity. (Ang et al. 2002, 4)

Follow-up research in 2006 identified 'practical tolerance' as the main approach adopted by Australians to manage their everyday experience of cultural differences (Ang et al. 2006, 37). This research included a focus on intergenerational responses to multiculturalism and found that younger Australians of culturally diverse backgrounds do not feel completely accepted by mainstream society; and yet, paradoxically, what the researchers describe as 'interactive diversity' is becoming an everyday experience:

Many of these Australians have experienced or observed instances of prejudice, discrimination and intolerance first hand. However ... interactive cultural diversity is becoming increasingly mainstream. Younger Australians of culturally diverse backgrounds are more comfortable interacting with others of different cultural backgrounds and feel that multiculturalism in Australia has progressed a lot in the past 30 years. (Ang et al. 2006, 9) 
Many of the younger people interviewed for the SBS study tacitly accepted the Anglo-Australian core as the cultural norm. They expressed concern about separated and 'siloed' ethnic cultural groups, which was said to reflect a desire for 'intercultural connection' (Ang et al. 2006, 19). This acceptance was characterised as one in which Australians 'live and breathe' cultural diversity through their everyday lives. The ambivalence expressed by a significant minority is consistent with the 2017 Scanlon Foundation findings. Both sets of research uncovered concerns about living in a multicultural Australia. However, the Scanlon Foundation noted a starker contrast between the experiences of migrants and the general population, and identified 'trust' as one of the measures of inclusion expressed as a sense of belonging. The foundation's 2015 survey found that, among those who had arrived in Australia since 2001, indications of trust in others was 37 per cent, compared with 50 per cent at the national level (Markus 2016, 46). When the findings of both reports are taken together, it can be established that an increase in intercultural connectedness can generate a sense of belonging and inclusion. Processes that enable intercultural connectedness include those of multicultural arts practices.

\section{Everyday Multiculturalism, Conviviality and Interculturality}

Terms such as 'post-multicultural' and 'cosmopolitanism' are relevant to the multiple roles of the artist, as they provide different frames for understanding the daily experiences of living in a multicultural society (Noble 2011, 2009; Papastergiadis 2013b, 2013c). Rather than viewing cosmopolitanism (and other seemingly outmoded phases such as assimilation and cohesion) as a linear historical process, it can be experienced on any given day-at the corner shop, on the train, in the park, at the cinema and, occasionally, in the art gallery. However, the policy version of multiculturalism often bears little relationship to everyday experiences because of the increasing versions of difference that no longer conform to essential views of ethnicity:

This differentiation of difference makes the reified categories of ethnicity celebrated by multicultural policies increasingly unviable and, because of this, often results in social anxieties because this differentiation challenges how we manage differences. (Noble 2011, 830) 
Those everyday experiences can be described as cosmopolitanism. Cosmopolitanism comes from the original Greek meaning 'citizen of the cosmos' and has been refined to include the manner in which the citizen engages in the world as well as a moral imperative to do so:

Cosmopolitanism can be defined as a global politics that, firstly, projects a sociality of common political engagement among all human beings across the globe, and, secondly, suggests that this sociality should be either ethically or organisationally privileged over other forms of sociality. (James 2014, x)

Regardless of its scope (whether local or global), this ability to move between cultures is an acquired skill based on experience and proximity to others and, as such, is one of the competencies to help navigate difference:

The internationalist outlook of cosmopolitan multiculturalism enhances people's resilience in such a world. A cosmopolitan orientation to life entails openness towards different cultures, peoples and a general willingness to engage with 'the other'. (Ang, Hawkins and Dabboussy 2008, 21)

Many NESB artists are particularly well placed to adopt such an outlook and competency.

The ability to engage is receiving research attention, and is providing an alternative to the dystopic narratives around the 'failure' of multiculturalism generally presented in academic research (Wise and Velayutham 2013). This alternative comes from the observations that an 'ease' in everyday relations between ethnic and mainstream groups, or conviviality, is 'the processes of cohabitation and interaction that have made multiculture an ordinary feature of urban life in Britain' (Gilroy, quoted in Wise and Velayutham 2013, 407). This critiques 'fixed' notions of difference based on race and identity to go beyond the colonial position and 'carnivale multiculturalism' - the occasional celebratory showcase of difference. Wise and Velayutham suggest that Gilroy offers a resilient approach to living multiculturally because he highlights the satisfaction generated by small daily events that come from the 'creative, intuitive capacity among ordinary people who manage tensions' (Gilroy quoted in Wise and Velayutham, 2013, 407). This could also be described as a form of social resilience that exceeds the incapacity of those who simply tolerate, because the people Gilroy observes show the capacity to interact with each other. 
In Friction, Tsing (2005) describes the dynamic small gestures that groups and individuals use to disrupt the large-scale demise of the planet. In addressing cosmopolitanism and complexity, she reflects that: 'The challenge of cultural analysis is to address both the spreading interconnections and locatedness of culture' (122). The relevance of this challenge for arts practitioners can be seen both as a technique to make use of connections and as an inspirational form for artists navigating their multicultural arts practices.

Noble $(2011,827)$ attributes navigational agency to members of Australia's multicultural society because he sees that cultural difference is not juxtaposed, as in the 'mosaic' metaphor for multiculturalism, but is 'negotiated'. Social and cultural possibilities are presented as a dynamic relationship of 'interactive interculturality' (Ang et al. 2006, 23) that is more than an 'awareness' of difference, and is 'seen in the multiple forms of adaptation and mixing that mark the process of settlement, intermarriage, intergenerational change and the plural social contexts in which difference is negotiated' (Noble 2011, 827).

The issue of competence, however, sits at the centre of a successful engagement with such opportunities. Those with cosmopolitan awareness display their credentials by showing up in the first place, and by these appearances suggest that they have already developed a level of confidence to navigate and, if necessary, negotiate culturally complex events that require diverse 'transactional competencies' (Noble 2011, 838). Those who are not interested in acquiring the competency to act 'in-between' or do not feel confident in navigating cross-cultural events may choose not to participate. Herewith lies the 'friction' that is at the heart of the multicultural reality: the range of differences include different attitudes to engaging with difference. Art can be one of the vehicles to assist in exposure to difference and may in turn open up spaces for dialogue between differences.

\section{The Case for Addressing the Cultural Issue of Difference in the Arts}

Young adults of migrant parents have described themselves as having 'hybrid' cosmopolitan identities but, in a 2011 study, they did not tend to describe themselves as Australian (Collins 2013, 144). Nor did they recognise themselves as being visibly represented as Australians. Instead, 
they equated their ethnicity with social and cultural credentials attained through their diasporic families and capacity to engage through the internet and social media. Five years on, similar statements were expressed by the young artists interviewed for this book. The right to be represented as belonging to the nation and as national subjects has been one of the core areas of friction in the policy development of multiculturalism. As Cope and Kalantzis $(1997,264)$ observed 20 years ago:
Those custodians of the symbolic nationhood, the media, the arts and education, have been slowest and the most combative when faced with the need to modify norms, canons or representational imagery. This is now a critical challenge. For too long those interested in change have drawn a dichotomy between the economic-political and the symbolic. It is time to bring them together.

To bring the economic-political and symbolic together remains a critical challenge in Australia. Symbols are at the heart of cultural production and must be handled with care because of their potential power. Whose symbols and how new ones emerge are core issues that face artists, including those artists concerned with ethnic minority identities.

Stuart Hall $(1997,4)$ identifies the cultural role of the symbolic as crucial, both because it goes to the heart of social life, and because culture 'permeates all of society'. He explains that language, in the broad sense of the term (encompassing images, objects, gestures, texts, data and materials, etc.), constructs and transmits meaning. For Hall (1997, 4), language is the 'privileged' medium for the construction of meaning across 'all facets of the cultural circuit - in the construction of identity and the marking of difference, in production and consumption, as well as in the regulation of social conduct'.

The question of how to produce cultural representation varies according to context. The SBS Story by Ang, Hawkins and Dabboussy (2008) offers an in-depth description and analysis of the intricate politics and complexities of inclusion within Australian cultural production. It documents how Australia's national multicultural radio and television broadcaster, SBS, negotiates and presents Australia's multicultural society. Examining the challenges of cultural diversity in which multiple aspects of identity are clearly articulated, it argues that: 
For many people, ethnicity is not the all-important determinant of their sense of self. Arguably the capacity for individuals to explore their own place in society, irrespective of their cultural background, is one of the hallmarks of a successful multicultural society. (Ang, Hawkins and Dabboussy 2008, 46)

The authors, quoting former SBS Managing Director Malcolm Long's claim that, 'in the world that is coming, if you can't navigate difference, you've had it', present a succinct rationale for the benefits of cultural inclusion. They distinguish three phases in SBS's multicultural representation: ethno-multiculturalism, cosmopolitan multiculturalism and popular multiculturalism (Ang, Hawkins and Dabboussy 2008, 22). From the late 1990s, 'popular multiculturalism' positioned multiculturalism as the cultural norm, claiming it as the mainstream rather than the marginal (20). The concept of popular multiculturalism is of key relevance to this research and appears to have been a premature cultural claim given the continued low levels of participation in the arts by culturally diverse Australians.

Francois Matarasso (2010), a UK-based cultural researcher, speaks of shaping cultural identity-and having it be recognised by othersas being:

Central to human dignity and liberty. If people can't represent themselves culturally, how can they do so politically? If people are only imagined and portrayed by others, how can they be equal, autonomous and active members of society?

Matarasso (2010) suggests that a solution can be found in the arts because 'art is a great tool for intervening in culture'. There is also heightened interest and research in how the role of art leads to increased sociality. One recent study observed (in this case via music) the transformation of 'personal subjective experiences into collective collaboration' (Sorsa et al. $2017,1)$. Similarly, an affirmative link between a sense of belonging and culturally diverse artistic expression is inferred in research into cultural citizenship (Khan et al. 2017, 1).

According to the Australia Council, Australian audiences wish to see a fuller artistic expression of the country's cultural diversity. Australian audiences want cultural diversity in what they see, listen to and read, and less than two-thirds of people think the arts 'reflect the diversity of Australian cultures' (Australia Council 2014a). In 2016 Australia Council data analysed by market research company Morris Hargreaves Macintyre 
(2013) indicated that 75 per cent now held this view (Australia Council 2017e, 12). Further, Australia Council data from 2017 suggest that 64 per cent of respondents think the arts have a big or very big impact on our understanding of other people and cultures (Australia Council 2017c). These varied results highlight the mercurial nature of cultural statistics, yet also bring to the fore the desire for cultural production that is relevant to Australian society. The data also raise questions about the effectiveness of the policies developed to address the imbalance of NESB artists' production, dissemination and audience development.

\section{United Kingdom and Canada: Issues and Responses to Cultural Diversity in the Arts}

The development of arts policy responses to cultural diversity takes place internationally. The UK, for example, regularly revises its equity legislation through its Equality Act 2010, in part because of its European Union commitments. The similarities between Australian and Canadian histories of indigeneity, colonialism and migration, which have resulted in highly culturally diverse populations, makes a comparison of arts policies in the two countries prudent.

\section{Arts Council England}

Established in 1946, ACE is an agency of the Department for Culture, Media and Sport (DCMS) and has had equity policies, including for Black, Asian and minority ethnic artists (BAME), in place since the 1970s (ACE 2011, 5). The Australia Council for the Arts is modelled on ACE. As part of a regular review of ACE, DCMS commissioned former Edinburgh festival director Brian McMaster to report on the most effective use of public funds towards the arts. He identified:

The profound value of arts and culture. Just as the new society we live in has immense potential for the creation of art, so art has never before been so needed to understand the deep complexities of Britain today. (McMaster 2008, 5)

The need for art to contribute to understanding society is often cited as a beginning point for such reports; however, the McMaster report reinforces this point by articulating diversity as one of eight key areas 
of recommendations. McMaster $(2008,9)$ 'refutes' the association of excellence in the arts with exclusivity, heritage and elitism, instead viewing it as a process that 'takes and combines complex meanings, gives us new insights and new understandings of the world around us and is relevant to every single one of us'.

McMaster $(2008,11)$ perceives that, to be relevant, a commitment to diversity 'must run through' the concepts of excellence, innovation risk-taking and participation:

The diverse nature of 21 st century Britain is the perfect catalyst for ever greater innovation in culture and I would like to see diversity put at the heart of everything cultural. We live in one of the most diverse societies the world has ever seen, yet this is not reflected in the culture we produce, or in who is producing it. Out of this society, the greatest culture could grow. Culture can only be excellent when it is relevant, and thus nothing can be excellent without reflecting the society which produces and experiences it.

These statements are akin to Australian discourse regarding the yet to be realised potential that cultural diversity offers to a vibrant culture. The claim to inspire change occurs by placing diversity as a central tenet of art and cultural production.

Taking up the process to amplify issues of diversity, in 2009 ACE commissioned Third Text to heighten the debate 'about diversity and the arts to a new and different level' (ACE 2011, 4). Third Text is a longstanding journal dedicated to issues of the arts and diversity edited by Rasheed Araeen. There are two other longstanding UK 'flagship' companies: Rich Mix (Mirza 2009), which is dedicated to diversity in performing arts; and iniva (Institute for International Visual Art), which is dedicated to diversity programming and discourse in the visual arts. These two companies lead the production and critique of work by BAME artists. The resulting report, Beyond Cultural Diversity: The Case for Creativity, included claims from UK-based critical thinkers and writers that Britain's state-sponsored policy of cultural diversity had failed (Appignanesi 2010, 5): 'Some of us in Britain are being cast as outsiders who require a domestically engineered foreign policy'. The report called for a 'culturally integrated future' that surpassed cultural diversity, included government statements on leadership within the frame of the arts, and promoted an 'arts and artists-led approach to diversity and equality' (ACE 2011, 16). 
Arts professionals were asked to own and creatively adapt ACE policies on diversity and equality and to 'probe (and) innovate creative approaches and solutions' (ACE 2011, 16).

Diversity is seen as a core driver of creativity by ACE, and no longer as a deficit burden, drawing from business models that connect the 'characteristics of resilient organisations and the embracing of creative diversity' (Nwachukwu and Robinson 2011, 5). This link to resilience echoes the concerns of the 2017 Scanlon Foundation report discussed earlier. The Creative Case for Diversity (hereafter Creative Case), launched in 2011, is ACE's diversity policy based on equality, recognition and a new vision. The new vision moves from a deficit model to one that articulates 'an approach that encompasses the ways in which diversity has been and remains an intrinsic and dynamic part of the creative process' (ACE 2011, 4).

ACE's approach affects all subsidised sectors of the arts and, in particular, supports those who excel at incorporating diverse influences and practices relevant to British populations. Activities across six themes identify whether subsidised national portfolio organisations (NPOs) are actively pursuing the Creative Case. The themes relate to artistic programs, talent development, barriers to artistic involvement, resourcing and monitoring, self-evaluation and sector leadership. ACE (n.d.-a) positions diversity at the centre of the Creative Case as a sustainable strategy for the arts, because its view is that diversity is able to:

Address other challenges and opportunities in audience development, public engagement, workforce and leadership. Our funded organisations are expected to show how they contribute to the Creative Case for Diversity through the work they produce and present.

This expectation follows through in ACE's funding decisions for 201822. The Bush Theatre, based in the culturally diverse London suburb of Shephard's Bush and known for its creative direction and BAME development under Madani Younis, received a 20 per cent increase, while Hampstead Theatre, which has not produced work across the equity areas, had a 14 per cent decrease in funding. This is seen to reflect:

That in the 21st century who you choose to work with, and how you work with them, is part and parcel of artistic policy. Arts organisations can't continue to work on outdated models and expect to secure funding. (Gardner 2017) 
Part of ACE's 'new vision' is to support the companies whose traction for diversity is evident. ACE also has clear equity objectives for BAME, disability, gender and sexual orientation across artistic outcomes, workforce and governance participation (ACE 2016, 6). The Creative Case recognises diversity as the central tenet for innovation to which UK£11 million strategic funds have been allocated-approximately 10 per cent of the country's annual expenditure (ACE 2016, 6; n.d.-b).

The Creative Case sits inside the British Government's Equity Policy, whereby each department must deliver equitable inclusion and demonstrate accountability across a range of measures, including equity in employment and governance roles. To this end, ACE publishes the employment data generated by arts organisations. They report that BAME employment in the arts is now at 17 per cent compared to an average of 15 per cent in broader employment contexts (ACE 2016, 7). The implication that, since 2011, BAME artists and organisations have been leading in terms of the cultural diversity of the workforce lends credibility to ACE's claim as to the effectiveness of an arts-centred approach to diversity.

Another ACE strategy allocated UK£5.3 million to 'elevate' (ACE's words) the many small organisations that have always had diversity as their creative focus by building their capacity to successfully apply for more substantial funds in the future, thereby increasing the diversity of the organisations supported through NPO funds (ACE n.d.-c). In this manner, Creative Case for Diversity addresses the structural barriers faced by artist-run small companies that create important access spaces that enable diverse participation.

Arts sector debate is enabled in various ways: for example, through live interactive webcasts of conferences—such as Creative Case: Leading Diverse Futures, which included presentations from the chair of ACE, artists, bureaucrats and administrators (ACE 2018); and through Arts Professional, an online arts news and information resource, which featured a series of monthly debates on diversity for organisations and practitioners in 2017 (Richens 2017). In addition, ACE develops resources to inform companies about how they can increase diversity in their sphere of the arts: tool kits for governance (e.g. how to produce an 'Equity Plan'), tool kits for increasing diversity in creative projects (e.g. how to attract talent and leaders from diverse backgrounds) and equity data on diversity employment in each funded company (ACE 2016, 2018). The striking element about ACE's approach, particularly over the past decade, is that 
Creative Case systematically addresses structural barriers to diversity by tying funding agreements to outcomes that increase diverse participation, creative content, employment and governance.

\section{Canada Council for the Arts}

The CCA was established in 1957 'to foster and promote the study and enjoyment of, and the production of works in, the arts'. Interestingly, and creatively, the minister responsible for the arts is also responsible for Canadian heritage and multiculturalism, which places art within a strong cultural environment (CCA 2018). This sends a different signal of importance to that of Australia, where the federal arts portfolio is usually associated with communication or entertainment activities. Another distinction is that the CCA is responsible for the Canadian Commission for UNESCO. The commission's aims are to encourage a Canadian society in which knowledge and learning is shared, locally and globally, so as to 'build peaceful, equitable and sustainable futures' (CCA 2018). As in Australia, the CCA 'firmly believes' in the effectiveness of peer assessment to allocate funds and works cooperatively across various governing jurisdictions. The four commitments of the CCA are to increase support to artists, amplify Canadian art through digital means, renew the relationship between indigenous artists and audiences, and raise the international profile of Canadian artists (CCA 2018).

The following brief analysis is drawn from the CCA's policy statements and published critiques, which suggest that similar frissons between artists and the workings of the council occur in Canada and Australia. The 2017 CCA Equity Policy specifies an understanding of, and approach to, the term 'cultural equity'. The preamble positions the CCA's approach squarely within UNESCO's (2001) sustainability agenda and rights-based diversity of cultural expressions:

Cultural diversity is not only a necessary element in the development of the arts, but also an essential factor in developing sustainable human societies. This diversity needs to be reflected in the arts to counter homogenization of artistic expressions and inequitable distribution of resources, so the next generation of citizens can fully achieve their artistic potential and exercise their cultural rights. (CCA 2017, 9) 
Like the Australia Council, the CCA has responded to ongoing concerns of equal representation. Such pressures have come from within the institution as well as advocacy by First Nations artists and artists of colour (Fatona 2011, 108). Yet, it was government intervention that generated deeper awareness:

The practices of government, including multiculturalism and its policies, found their way into the Council, highlighting the ways in which the state and the social and political are intertwined and are difficult to disentangle. (Fatona 2011, 116)

It was not until the early 1990s that the need for a policy was instituted at the CCA and, again, as with the Australia Council, the work had been established mainly through the 'community arts' funding section. In the case of the CCA, this was known as the 'Explorations Program', which worked with ethnic and minority cultures within the arts:

We were doing what they called multicultural work at the time in the Explorations Program recalls [former CCA staff member] Creighton-Kelly ... 'In a sense, the genesis of work directly concerned with cultural diversity occurred in the Explorations Program'. (Fatona 2011, 154)

The policy recognises that marginalised cultures, because of 'cultural differences, systemic barriers and uneven resources', deserve 'financial, infrastructural and public policy support comparable to the dominant culture of a society' (CCA 2017, 9, emphasis added). The idea of comparable investment is bold, yet raises a number of issues and challenges, such as defining the scope of 'comparable', understanding the means to achieve 'comparable' and resourcing a proportionate level of investment.

The most obvious difference between Australia and Canada is the lived reality of bilingualism; however, bilingualism results in similar issues as multilingualism, as 'Francophone and Anglophone cultures assume dominance over other cultures' (Fatona 2011, 108). The resonance of multilingual streetscapes also hovers across both countries.

As regards policy, the CCA adopts the umbrella term of 'equity-seeking groups' to define who may benefit from, and seek, 'specific measures to improve access to programs and funding support' (CCA 2017, 7). The term is striking in its apparent simplicity, yet it holds the suggestion of a lack and the desire to participate in the 'mainstream', a quasi-condition that could concern some artists who wish to remain marginal. The CCA 
names the groups it includes as 'equity-seeking' as 'visible minorities', and uses the term 'culturally diverse' to 'respectfully identify racialized groups. These are Canadians of African, Asian, Latin American, Middle Eastern and mixed racial heritages' (CCA 2017, 7).

As in Australia, indigenous artists are considered separately and also have diverse heritages, being First Nations, Inuit and Métis peoples (CCA 2017, 8). There are specifically articulated policy statements regarding who the groups are and why they are supported for equity considerations. Notably, unlike the Australia Council, the CCA allocates resources to implement strategic initiatives dedicated to realising equity policy intentions (CCA 2017, 14).

Committees continue to form the structure for monitoring, reporting and strategic directions. In the 1990s, not dissimilar to the Australia Council Multicultural Advisory Committee (ACMAC), a Racial Equity Committee that included 'racialized artists' assisted a consultant to undertake policy development. A 'First Peoples Advisory Committee' was subsequently formed in recognition that their similar issues 'diverged because of historical differences in the groups' relationship to the Canadian nation-state'. Fatona $(2011,110,113)$ notes that addressing 'equity, access and new practices' has been seen as an urgent requirement. By addressing these needs together, the potential for the stigma of equity and access may in some way be ameliorated when associated with 'new practices' of digital arts.

In 2019 the CCA Board was made up of artists, arts company heads, mining and financial industry members, and a First Nations filmmaker (CCA n.d.). The CCA's investment in arts grants is aligned to their strategic priorities. The external jurors or grant assessors are reminded of these at the beginning of the process:

They give you a list of the council's priorities. I think there were about five priorities last time I was there. And they're very typical ones; they're like we should take into consideration cultural diversity, for example. (D’Andrea 2017, 251)

Attention to cultural diversity appears to have gained traction. The CCA's 2019 annual report notes that the council's support for indigenous artists, groups and organisations increased by 35 per cent; for culturally diverse and 'official language minority communities' by 24 per cent; and for deaf and disabled artists by 48 per cent (CCA 2019, 16). In 2018-19, 
the CCA allocated CA $\$ 242.7$ million, of which CA $\$ 49.2$ million went to individual artists; of that, a very encouraging 842 grants were awarded to 'culturally diverse artists', totalling more than CA $\$ 25$ million (CCA 2019, 24).

ACE, the CCA and the Australia Council all claim that demographic diversity is the defining element of their identities, and that arts and culture benefit from this diversity in terms of creative expression and innovation. They each face challenges to fully realise these creative expressions in an equitable way, as do artists in these countries who strive against the wheels of a Western canon. The CCA's investment in culturally diverse artists is 'encouraging' to use their term. My focus on the Australian context gives pause to reflect on the benefits yet to be garnered from a shared international discourse on these issues.

\section{Australian Cultural Policy}

\section{Australian National Cultural Policy}

The policy to tie Australian funding to particular outcomes is one that wanes far more than it waxes in the arts. Government support for the arts has been slow and limited. Committees, such as the Commonwealth Literary Fund (1908) were established in Australia at the time of Federation or soon after, but it would take 65 years before a government agency was established. The Australian Council for the Arts, based on the British and Canadian model of 'arm's length' or distance from government interference, was established in 1973 by Prime Minister Gough Whitlam, who noted the lack of an Australian cultural policy, which would take a further 20 years to be tabled (Gardiner-Garden 1994). The Australia Council has, from 1975 onwards, had a history of awkward relationships with governments and oppositions alike, experiencing administrative and funding shifts on a regular basis. Even the almost sacred tenant of 'arm's length' decision-making has been critiqued for neither adequately 'insulating' the Australia Council from political demands, nor providing a valuable firm presence in Cabinet (Macdonnell 1992). The 1988 Coalition shadow minister Chris Puplick saw it as an 'excuse for Ministers to avoid their responsibilities to define and promote a national arts policy' (Gardiner-Garden 1994, 35). 
There have been two, albeit short-lived, federal cultural and arts policy statements, both of which established connections between cultural diversity and creative expression: Creative Nation in 1994 and Creative Australia in 2013. As the federal arts agency, the Australia Council developed specific multicultural arts policies that built on, and reshaped, the 1970s era of ethnic arts that 'remained trapped within the rhetoric of welfare' (Hawkins 1993, 120). The Australia Council's policy statements on Arts in a Multicultural Australia (AMA) in 1993, 1996, 2000 and 2006 stand out as periods of policy attentiveness and resourced activity.

Creative Nation (Department of Communications and the Arts 1994), launched by the Keating Labor Government in 1994, promoted a broad approach to culture that included areas such as film, media, libraries and heritage. Framed by this creative pluralism, it is important to note this document's direct reference to Indigenous and migrant cultures as central in shaping Australia's domestic and exported identity. But, as Stevenson (2000) notes, the arts agenda continued to inadequately deal with the creative priorities of ethnic minorities. Creative Australia, launched almost 20 years later (Parliament of Australia 2013), made similar connections, but compounded the sense that political leaders are ambivalent about multicultural arts practices. Khan, Wyatt and Yue $(2014,1)$ commented that:

Creative Australia contains very limited references to multicultural arts, and outlines no policies explicitly directed at expanding the participation of migrant or ethnic communities in the nation's arts and cultural sectors. Instead, cultural difference in the arts is referenced obliquely within a broader category of 'diversity'.

Developed out of the national consultation process of the 2020 Summit, Creative Australia generated high expectations in the arts sector for clear direction and leadership. The 101 members of the 'Towards a Creative Australia' reference group included a handful of NESB artists and arts workers; however, it is not clear how influential the group was in formulating the five main goals of the final policy document. These goals included recognising Aboriginal and Torres Strait Islander culture, supporting excellence and innovation, and expanding capacity in 'all aspects of national life'. The second goal was expressed in the least active language: to 'reflect' the diversity of Australian citizens, including 'cultural background, location and social circumstance' (Parliament of 
Australia 2013). According to Khan et al. $(2013,28)$, the Creative Australia policy dissipated multicultural objectives 'via the language of diversity, into a range of economic, social and cultural governmental agendas'.

Ambiguity about who or what was meant by 'diversity' steered the focus away from identifying specific groups. This had the effect of confusing arts organisations as to where their 'inclusion' agenda, if they had one, could be directed:

Drawing multicultural policy back into an instrumentalist, welfarist agenda that is also targeted at 'community' has the effect of decentring it from narratives of the nation state. This displacement means that the language of 'multiculturalism' no longer carries the same symbolic status it did in Creative Nation, where it was explicitly incorporated into a vision of Australian society. (Khan et al. 2013, 29)

The Creative Australia policy disappeared with the change of government following the September 2013 federal election. Australia's cultural policy was in limbo, in effect leaving the 2006 AMA statement as the policy on multicultural arts under the umbrella of the Australia Council's strategic plan of May 2014. The unexpected and fractious budget reallocation to the Arts Ministry announced in May 2015 caused a significant rupture between the major performing arts (MPA) companies quarantined from cuts to the Australia Council budget, and increased competition between artists, especially smaller and medium-sized organisations. The Turnbull government (from September 2015) continued the call for 'excellence' as the fundament for the arts, and stipulated a quarantine from funding cuts to MPA companies. This being the only word from the current government on funding to the arts, by default, it must be read as the Coalition's current cultural policy.

\section{State Cultural Policy Statements}

The national context provides additional layers of policy. Australian state and territory governments enact their own arts and cultural policies that also interact with their local government areas and the federal government's arts agency. The strategic directions of four state arts departments provide insight into the positioning of the arts in a multicultural context. Moving from west to east, the Department of Culture and the Arts (DCA) in 
Western Australia released its Strategic Directions 2016-2031 in 2016. This document views multiculturalism in WA as 'an obvious asset' in their challenge to 'attract and retain' artists:

The role of our State and community collections in reflecting our identity, culture and environment will become increasingly important for full citizen engagement to contribute to social cohesion, authentic Western Australian branding and meaningful storytelling around a shared identity. How we include our most creative people into our civic decisions will be one of the most important challenges in reaching 2031. (DCA 2016, 16)

Notwithstanding this compelling role, the action to 'better [reflect] our multicultural population in our artistic and cultural output' (DCA 2016, 32) sits as one among 30 actions despite it being one of their most important issues.

South Australia is the next state moving eastwards and their Arts and Culture Plan South Australia 2019-2024 was launched in 2019. It refers to 'new communities of people from a range of cultural backgrounds, including growing international student communities, [that] represent opportunities for diverse forms of cultural engagement and dialogue across all ages' (Department of the Premier and Cabinet 2019, 11). One of the plan's four values is: 'Embracing diversity_promoting inclusion and encouraging new voices and approaches across all demographics' (6). The intention of this value, without being specified as such, must be to attach to each of the six goals that, aside from a focus on Aboriginal and Torres Islander arts, do not detail multicultural engagement.

Creative Victoria's Creative Industries Strategy 2016-2020 provides specific detail around how it will continue to improve its 'Access and Diversity' goal. This goal faces the challenge that there is 'still work to be done to ensure that diversity in our cultural products and experiences reflects the diversity of our population' (Creative Victoria 2016, xx). To address these challenges, Creative Victoria flags its serious intentions by dedicating funds and articulating strategies. AU $\$ 32.15$ million was allocated over four years to 'improve access to, and participation in, cultural activities', which includes audience engagement as well as employment in the arts (27). This strategy extends to awareness training in the creative sectors that receive government funds. In conjunction with peak organisations including Arts Access Victoria, Aboriginal Victoria and the Office of Multicultural Affairs and Citizenship, the expectation is that funded creative organisations will 
develop appropriate access, diversity and inclusion plans as well as the requisite training to improve workforce diversity and engender greater diversity in programming and participation' (28).

The most eastern and populous state is New South Wales. Its state arts department, Create NSW, released its 10 year Arts and Cultural Policy Framework in 2015 and, similar to the Australia Council's 2000 and 2006 AMA policies, it defines multicultural NSW as a strength of its innovation goal: 'New pathways and opportunities will draw upon NSW's great strength—our cultural and linguistic diversity' (Create NSW 2015, 10). Create NSW also articulates the need for leadership for institutional and organisational governance, cultural programming and employment:

The State Cultural Institutions will also work to reflect the diversity of NSW's population in all aspects of their organisations, including more culturally relevant programming. Arts NSW will work with funded organisations to promote a workforce that reflects the diversity of NSW's population. (Create NSW 2015, 36)

The NSW framework, as with other states, includes case studies of creative projects. In the case of NSW, the artworks provide dynamic insight into the creative work that stems from the state's multicultural artists.

A consistent theme surfaces across these four states about the relevance and importance of demographic diversity to a creative future. However, Victoria is the only state from this brief analysis to attach financial investment to realise an increase in participation.

\section{The Role of the Australia Council: Multicultural Arts Policy}

The Australia Council began taking an interest in the structural inclusion of ethnic groups in the mid-1970s, eventually leading to the establishment of ACMAC (Blonski 1992, 10; 1994, 202-03). The first meeting of the Australia Council's Migrant Committee in 1975 considered two models for the inclusion of 'migrant artists' into the remit of the Australia Council. The Aboriginal Arts Board's 'parallel' model or a distributed model in which all boards took on responsibility for 'reflecting "the multicultural reality of Australian society" (Blonski 1992, 15). This issue of the positioning of multicultural arts within the institution would be a recurring theme for the council and its advisers (see Appendix B). The Migrant Committee 
recommended increased membership from a wide range of ethnic groups, advertising programs in ethnic media, consistent financial and advisory programs, and that their title be changed to 'Ethnic Arts Committee' (EAC) to better reflect their role (Blonski 1992, 15). The relationship with Aboriginal and Torres Strait Islander Arts (ATSIA) was also on the committee's agenda from its inception. After several years, ATSIA joined the EAC to present a united presence supporting difference in the arts.

One of the key issues faced by EAC and ATSIA was the schism between practices of cultural maintenance and new art production based on a criteria of 'excellence'. The assumption was that 'cultural maintenance' falls outside the regime of excellence. Kalantzis and Cope (1994, 13) elucidate the impact of confusions and contradictions in this criterion, 'showing the concept of excellence in the arts to be a contested one ... linked to particular ideological positions'.

Decisions about excellence as one of the 'elite' systems of exclusion are discussed in Access to Excellence (Kalantzis, Castles and Cope 1993). This series foregrounded the barriers and reviewed the means by which access is denied based on a narrow perspective of what constitutes excellence in the arts. Tim Rowse (1985) suggests that, despite Australia Council Chair Dr Timothy Pascoe questioning the use of 'excellence' as an assessment criterion, the early days of the Australia Council are imbued with a narrow perspective. Rowse $(1985,33)$ sees excellence as a 'language of the powerful, which effaces the social basis of that power' and argues, presciently, that it will 'probably continue to be a persistent rhetoric'. He explores the way this rhetoric is established as myth-as utopian in the homogeneity of its single scale of values - and contends that the notion of excellence attempts to distance art from 'grubby' politics and monetisation (Rowse 1985, 34).

A third utopian element can now be added to Rowse's discussion. The Australia Council's stated mission is to move away from 'homogeneity', suggesting that Australian society should be reflected in the participation and engagement in the arts as 'arts without borders' (Australia Council 2017b, 10). However, this means nothing if the funds and the structural mechanisms are not present, and are not centre and front of the institution. Historical accounts of the arts in a multicultural Australia challenge the rhetoric of inclusion that the arts will, in a regular and normalised manner, fully reflect multicultural Australia. 
The two most recent Australia Council policies that focus on multicultural arts are those of 2000 and 2006. AMA 2000 highlighted the roles of tradition and innovation in creativity and profiled individual artists' practices as well as their roles in community settings. By taking this focus, the policy attempted to alter the perception that multicultural artists were relevant only in a community setting, with its attendant lower status in the arts world. AMA 2006 highlighted the need to incorporate 'the diversity of our cultures' through leadership, participation and creative production, including cross-cultural exchange between Indigenous and NESB artists. Since 2008, the AMA policy has been subsumed under the umbrella of the Australia Council's Cultural Engagement Framework.

\section{Multicultural Arts Practices}

\section{Issues of Creativity}

Creativity is considered to be the profound and defining characteristic of humanity. It is the 'innate quest for originality' and can be 'judged by the magnitude of the emotional response it evokes' (Wilson 2017, 3). The concept of originality carries with it subjective recognition as to what constitutes the 'new' and the potential for challenges to be generated in society because of that newness:

Whether on the temporal, phenomenal, or social plane-the new is not objectively existing, but it always depends on schemes of interpretation, which are more often than not controversial. Social regimes of the new, as they are characteristic of modern societies, do both: they observe the new and they prefer it to the old. (Reckwitz 2014, 25)

Using this lens, Reckwitz could conceivably be writing about the challenges faced by NESB artists when raising the issue of 'interpretation' and who decides what is new, and, therefore, of value. This may include social challenges, such as a lack of understanding about, and support for, NESB artists' work by mainstream arts agencies, and creative challenges, such as when NESB artists bring traditional forms, usually associated with their ethnicity, into conjunction with contemporary art practices. The newness, or 'unexpected[ness]', brought about through creativity is also seen to stem from the recognisable (Hastrup quoted in Svašek and Meyer 2016, 3). Those wishing to make the new 'cannot escape the intertwining of past, present and future' (Derrida quoted in Svašek and Meyer 2016, 3). 
Art is even more elusive to define. The following is among my favourite contemporary descriptions because it evokes the potential, risk and power of symbols that endure:

I can't tell you what art does and how it does it, but I know that art has often judged the judges, pleaded revenge to the innocent and shown to the future what the past has suffered, so that it has never been forgotten. I know too that the powerful fear art, whatever its form, when it does this, and that amongst the people such art sometimes runs like a rumour and a legend because it makes sense of what life's brutalities cannot, a sense that unites us, for it is inseparable from a justice at last. Art, when it functions like this, becomes a meeting place of the invisible, the irreducible, the enduring, guts and honour. (Berger 1992,9)

The 'meeting place of the invisible' conjures, for me, the sites of multicultural arts breaking through into visibility regardless of which medium the work stirs from. A more direct definition suggests that 'art is a powerful tool to redress and reimagine our world' (BDL Museum 2018). This definition also sits comfortably with how NESB artists may develop their practice.

British-based art theorist Araeen describes the difficulty and importance of creating and presenting culturally diverse artwork:

An enormous confusion reigns about cultural diversity, which has obscured both the question of its necessity to society and also its relationship to creativity ... Only when people have freedom to think, to reflect and contemplate, can they confront the norms that have become fixed dogmas, and so reactivate society's creative energy. In other words, new ideas produced by individual creativity, underpinned by freedom of thought, create a society able to change and transform itself into a dynamic force in history. (Araeen 2013, 95)

Araeen's claims of transformation based on cultural diversity resonate with the McMaster report, placing diversity at the centre of innovation. Both are advocacy documents written for a range of art decision-makers and artists. Each type of discourse reinforces the central themes of the other and points to the influence that cultural theorists and bureaucrats can garner to make the social and cultural case for diversity in the arts. The ways this transformation can occur are multi-platform and multisited, building upon opportunities and creative constraints. 


\section{Participation by NESB Artists}

Cultural economists recognise that a measure of culturally inclusive multiculturalism rests on the participation of artists in contributing to cultural formation:

One of the most important roles for the arts in this country is in celebrating the cultural diversity of contemporary Australian society. There are many professional artists in Australia who specialise in creating and re-creating art derived from a wide range of cultures, especially in the performing arts of music, dance and theatre. Artists from a non-English speaking background (NESB artists) also pursue their professional practice in the mainstream, often enriching their contribution through the influence of their particular cultural heritage. All of this activity is a vital element in the evolution of Australia as a truly multicultural society. (Throsby and Hollister 2003, 71)

The 30-year longitudinal study into artists' incomes in Australia, Making Art Work: An Economic Study of Professional Artists in Australia, reveals some improvement in the circumstances of NESB artists (Throsby and Hollister 2003; Throsby and Zednick 2010; Throsby and Petetskaya 2017). Yet, the capacity of the arts to contribute to this rich diversity is circumscribed by economic and other factors. In 2017, 10 per cent (an increase from 8 per cent) of professional artists were of a non-English speaking background, compared to 18 per cent in the general workforce (Throsby and Petetskaya 2017, 143). By comparison, the proportion of English-speaking background (ESB) artists (78 per cent) was higher than the proportion of ESB employees in the general workforce ( 73 per cent) (Throsby and Zednick, 2010). The slight increase in NESB artists professional participation-from 8 to 10 per cent-does not translate as an arts specific increase, because it has kept pace with the 2 per cent increase of NESB participation in the general workforce-from 16 to 18 per cent (Throsby and Zednick 2010, 23; Throsby and Petetskaya $2017,142)$.

More detailed data reveal that visual arts and craft maintain the highest proportion of professional NESB artists at 16 and 14 per cent, respectively; composers make up 8 per cent; musicians and community arts and cultural development (CACD) workers make up 7 per cent; and writers comprise the lowest proportion at 6 per cent (Throsby and Petetskaya 2017, 143). The most significant increase is that of acting and directing 
in live theatre, which, at 13 per cent, is up from 5 per cent in 2009. Language-based arts, such as writing and acting, are considered to be the most challenging for NESB artists, and CACD work is considered to be the most accessible due to local councils' use of arts in communicating with their 'multicultural communities' (Throsby and Hollister 2003, 23; Throsby and Zednick 2010,23). Historically, 'ethnic' artists were 'allowed' into the arts sector via the community arts door (Blonski 1992, 1994; Hawkins 1993, 86-88). The most recent data on the proportion of NESB artists across artform professions is shown in Table 1.

Table 1: Proportion of professional NESB artists in each artistic field, 2009 and 2015

\begin{tabular}{|l|c|c|c|c|c|c|c|c|}
\hline $\begin{array}{l}\text { Survey } \\
\text { year }\end{array}$ & $\begin{array}{c}\text { Visual } \\
\text { artist }\end{array}$ & Craft & $\begin{array}{c}\text { Actor/ } \\
\text { director }\end{array}$ & Dancer & Composer & Writer & Musician & CACD \\
\hline $2009^{*}$ & $14 \%$ & $14 \%$ & $5 \%$ & $10 \%$ & $4 \%$ & $4 \%$ & $6 \%$ & $3 \%$ \\
\hline $2015^{\star *}$ & $16 \%$ & $14 \%$ & $13 \%$ & $13 \%$ & $8 \%$ & $7 \%$ & $6 \%$ & $7 \%$ \\
\hline
\end{tabular}

* Throsby and Zednick (2010, 24).

** Throsby and Petetskaya $(2017,147)$.

NESB artists mostly work in visual arts and crafts; however, there has been a notable rise in the performing arts since 2009 when distinctions between artform practices were first published. The perception that NESB practitioners are mainly employed in CACD roles is challenged by the data. Table 1 indicates that NESB artists are not primarily found in CACD and that participation remains relatively low compared with other artforms. This result may reflect more robust research techniques, a high level of volunteering by NESB artists in CACD and/or a general decline in CACD practice (Throsby and Petetskaya 2017, 7). It may also reflect an upward trend in participation across the range of artforms.

The income gap from creative practice and arts-related activities (mainly teaching) between ESB and NESB artists has also shifted. In the 2002 and 2009 Making Art Work studies, NESB artists earnt 36 per cent less than the AU \$22,000 average creative income of their ESB colleagues (Throsby and Zednick 2010, 83). In the 2017 study, the income from creative practice increased to 95 per cent for NESB artists when compared to ESB artists (Throsby and Petetskaya 2017, 142). Earnings from arts-related activities were 18 per cent higher for NESB artists in 2009 but, in 2017, were 27 per cent lower than their ESB colleagues (Throsby and Zednick 2010, 83; Throsby and Petetskaya 2017, 145). Shifts such as these highlight the precarity of the portfolio careers that artists must engage 
with in Australia, and the agility with which artists must manoeuvre to maintain their practice. While it is heartening to see that creative income is reaching parity, it is cause for concern when NESB artists' ability to subsidise their income and have a broad presence across Australian arts reduced by 45 per cent between 2009 and 2017 .

Levels of public funding are another measure to gauge support to artists. In 2017, 18 per cent of NESB artists claimed that the largest barrier to their practice was the 'lack of access to funding or other financial support' (Throsby and Petetskaya 2017, 147) —a rise of 5 per cent (Throsby and Hollister 2003, 74). This links to the finding that, compared with ESB artists, 'fewer applications made for a grant, fellowship, residence, prize or funding are successful' - even though NESB artists had more success in grant applications at the Australia Council than with state art departments or local councils (Throsby and Petetskaya 2017, 147). The Australia Council claims an improved success rate of culturally and linguistically diverse (CALD) applicants. In March 2015, 20 per cent of all applicants identified as CALD and, of those, 19 per cent were successful; in March 2017, 23 per cent of all applicants identified as CALD and, of those, 29 per cent were successful, which indicates an increased success rate of 10 per cent over two years when compared within the CALD cohort (Australia Council 2017d, 17). These success rates indicate the high calibre of applications in the very competitive arena of arts grants. However, if these data are used to compare success across all applicants, the 29 per cent cohort of CALD artists' success represents an overall success rate of 5.8 per cent.

Despite their leaner economic position in the arts, in an earlier Making Art Work study, 60 per cent of first-generation NESB artists felt that their ethnic backgrounds benefited their careers while 15 per cent cited a negative impact (Throsby and Zednick 2010, 24). In 2017, 54 per cent identified an overall positive impact with an increase to 19 per cent of those who experienced an overall negative impact (Throsby and Petetskaya 2017, 145). For one-fifth of an artist population to identify negative consequences suggests significant issues are preventing their full participation.

These published data provide a detailed view of the situation for NESB artists and those organisations dedicated to their support and promotion. The picture that emerges is one of consistent underemployment in the arts of NESB artists when compared to the rest of the NESB population, 
and lower levels of arts grant funding across all categories in comparison to ESB colleagues. These data suggests that, should Australians wish to see cultural diversity in the art produced and experienced in this country, a policy response could improve the situation. Rowe et al. $(2016,12)$ observe that 'policy provides the articulation of field problems and solutions by setting and shifting agendas, validating actors and directing funding and technological resources'. Therefore, it is useful to look at the relationship between multicultural demographics and arts policies that aim to encompass and support the range and types of multicultural arts practices.

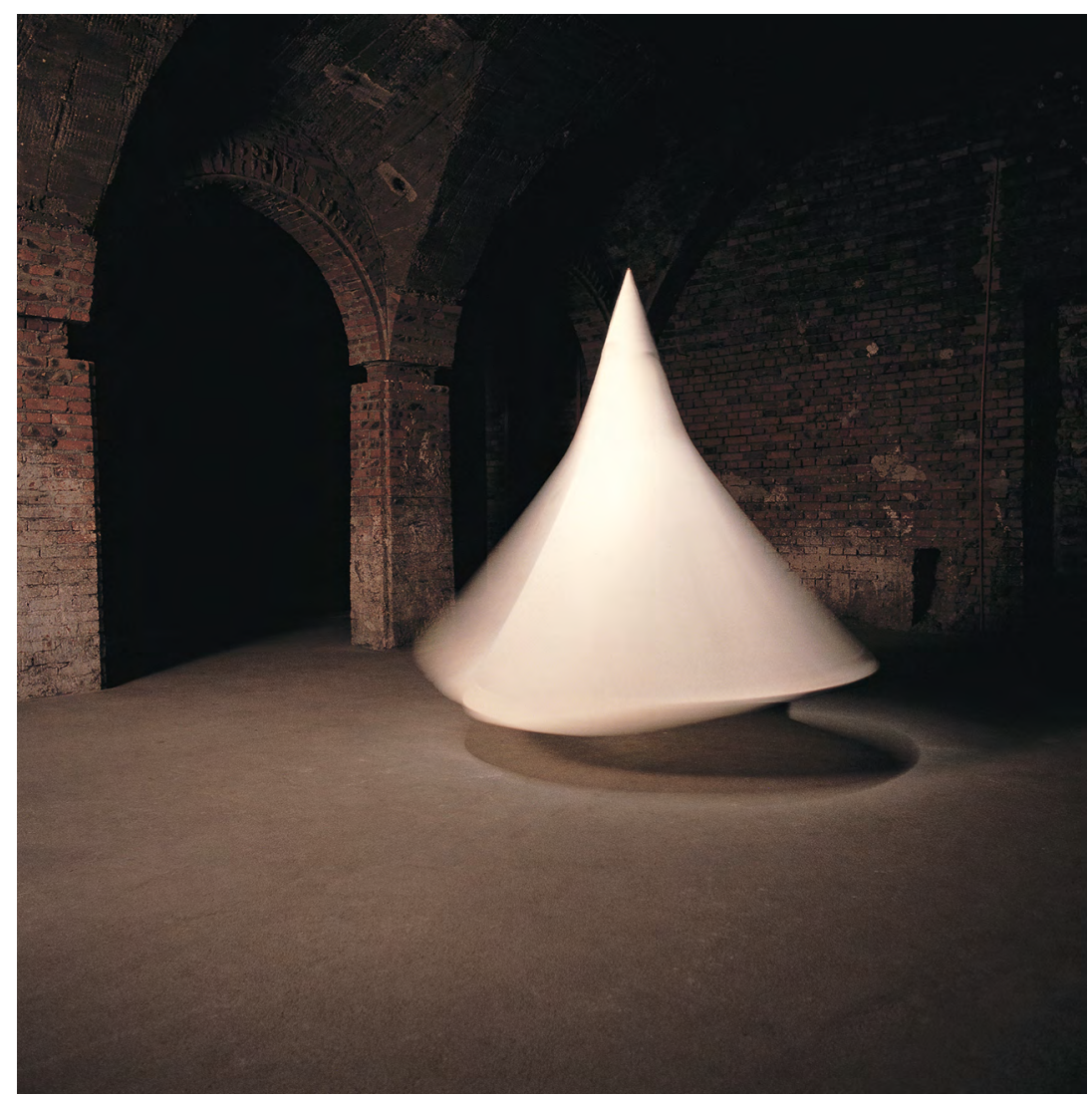

Image 3: Hossein Valamanesh, The Lover Circles His Own Heart, 1993

Silk, electric motor

Collection: Museum of Contemporary Art Sydney

Photographers: M. Michalski and B. Wojcik 


\section{Types of Multicultural Arts}

There is an inherent creative response in all migration: through 'an internal dialogue, the migrant compares the old home with the new, making with luck some creative novum out of their disparities' (Cubitt 2005, 315). All artists have a desire to make works that are affective and potentially transformative to individual audiences and, for some, to social groups as well. There are artists who choose to concentrate on their individual practice and accept the constraints and opportunities afforded by existing contemporary art infrastructure. Many of the artists interviewed for this study describe their need to be able adapt to, or stretch beyond, the systemic barriers they can face in the arts in Australia, some working within existing structures and others devising their own. Interdisciplinary or intercultural elements and collaborations are often considered as a foundation for creating environments to encourage innovation, and have emerged as the most contemporary ways in which artists navigate their presence into the arts scene. There is, however, an apparent tension that emerges when a claim is made for the potential for innovation because of a multicultural context.

Historically, 'multicultural arts' has been relegated to the sidelines as outdated and, by implication, mediocre, because of the association with cultural maintenance that sets it aside (Blonski 1992, 1994; Hawkins 1993; Khan, Wyatt and Yue 2014). It could be argued that, as a response to this kind of criticism (as simplistic) and perception (as static), NESB artists have developed a spectrum of creative processes to increase the possibilities of artistic innovation. The spectrum includes ethno-specific, intra-cultural, bicultural, intercultural, cross-cultural and, in more recent years, transcultural categories. These different processes come together under the umbrella of multicultural arts and the more general descriptor of 'hybrid'.

Ethno-specific refers to ethnic and linguistic groups who share the same race and ethnicity. When used artistically, the term points to the cultural traditions of specific ethnic groups and implies maintenance of those cultural 'traditions'. Hawkins $(1993,87)$ describes the inaugural funding for 'ethnic arts' through the community arts program of the Australia Council as having a focus that was: 


\begin{abstract}
Almost exclusively on support for the folk or traditional arts activities of non-English speaking groups ... the discourse of ethnic arts invoked tradition in a way that restricted the possibility of connections with other artforms and practices. It implied that migrants were essentially cultured and that their cultural expressions were pure and original.
\end{abstract}

According to Hawkins $(1993,86)$, this resulted in a 'narrow cultural ghetto for migrants'. It also may have contributed to the double-bind narrative that migrants are both valorised for their 'stories' and inherent knowledge of what constitutes 'culture', while simultaneously being shunned by creative peers for not being 'contemporary'.

In Australia in 2018, ethno-specific artists are most likely to be musicians, singers or visual artists and, if successful in gaining attention and an audience, tend to be slotted into the 'world music' or 'global art' genre. Ajak Kwai is a singer and storyteller who migrated from South Sudan to Tasmania and now lives in Melbourne. In 2006 she toured as part of the kultour program, which romantically described her performances as 'songs of the timeless musical traditions of her people, the Dinka of Southern Sudan' (MAV 2006a). This stage of her career is an example of multicultural arts as 'ethnic showcasing'-often perceived as a narrow view of multiculturalism that is static and limits cultural exchanges (Shigayuki quoted in Mar and Ang 2015, 9). Yet, as we see below, ethno-specific arts can also leverage from their traditional base into dynamic, creative shifts that alter the artists' work.

Rebetika, a form of jazz/blues first performed between the 1920s and the 1950s in Greece, is an ethno-specific artform that uses traditional instruments such as bouzouki. A group of Greek-Australian musicians and musicologists were part of the revival of this musical form in the 1980s, eventually receiving international recognition for their performances. A successful play was developed through a Multicultural Arts Professional Development project that celebrated this subcultural milieu. Café Rebetika, directed by Stephen Helper, toured Australia with kultour in 2011. Regular performer Demeter Tsounis appreciates Greek music and wants to 'have the opportunity to keep exploring and rediscovering it and performing it because it is such a treasure' (Tsounis quoted in Karavas 2009). 
Intra-cultural processes occur between artists of similar cultural backgrounds that may reinforce cultural traditions but can also lead to adjustments within a cultural form, depending on the context. Artists who perform cultural forms of traditional dance and music may be said to work intra-culturally. The Tawadros brothers use intra-cultural processes as composers and musicians. Joseph Tawadros is an oud player trained in Egypt who, it is claimed, 'single-handedly popularized the ancient instrument' (Radio National 2015). Joseph mainly plays with his brother James, both of whom live in Australia. Similarly, brothers Slava and Leonard Grigoryan are accomplished Australian guitarists originally from Kazakhstan. When these two sets of brothers perform together as Band of Brothers they present a more intercultural or bicultural process to their music.

Visual artist Hossein Valamanesh works in a minimalist contemporary style using materials from the earth to make two and three dimensional works that evoke his Iranian heritage. His use of materials, which could be from an Australian as well as Iranian landscape, and the motifs he employs - such as the twirling shape of a dervish, or items, such as oil lamps-lead to adjustments in the cultural form of contemporary painting and sculpture (see Image 3). Mar and Ang $(2015,8)$ argue that 'truly relevant and energetic creative work will come from working across cultures' when considering the diversity of cultural expression. There are several practices that arise from this process to generate art that has a more contemporary look and feel as well as having a closer context to much of contemporary life.

Bicultural creative processes link two (usually distinguishable) cultures or perhaps subcultures. Ajak Kwai fuses her musical sources in a bicultural process to (what appears to be) great success, performing at WOMADelaide, the National Folk Festival and the Melbourne Festival:

Whether Ajak is singing in Arabic, Sudanese or English she leaves you in no doubt as to the depth and richness of her Dinka roots. Music is the vehicle for her experiences as a refugee, exiled from her home town. Ajak and her songs take us on a journey deeply feminine, unique from the Upper Nile to gospel singing in Cairo to Melbourne where she has successfully fused her African roots with the grassroots of Australian music. (Kwai n.d.) 
Doppio Teatro, a South Australian-based Italo-Australian theatre company established by Teresa Crea and Christopher Bell in 1983, demonstrates the move from ethno-specific (originally they presented bilingual theatre by Italian playwrights) to bicultural writing in presenting theatre about the experiences of Italo-Australians. Crea explains:

The idea behind Doppio is to underline the duality that exists here in Australia for many people who have two cultures within themor rather, who have culture of origin plus their confrontation with the dominant culture, which is the common code we live by, the Anglo Australian culture. (quoted in Mitchell 1998, 133)

Doppio Teatro was known for its quality production values and also for its ability to respond to the changes in society through the influences that were included in their productions. It reinvented its purpose from a bicultural theatre company to one that explored cross-cultural themes.

Cross-cultural implies a number of cultures in 'dialogue', crossing their boundaries to generate artistic development. Cross-cultural experiences are ones in which cultural forms and identities are reshaped and give way to form new creative entities. This is complex and difficult to articulate on a stage. Nevertheless, in 1997, showing bold, creative leadership, Doppio Teatro rethought their purpose to become Doppio para//elo and:

Expanded its range of activities under the para//elo banner, giving them the 'space to work more broadly from a bicultural platform to a cross cultural platform'. Their work now draws on the group's Italian heritage as one of many ingredients in a contemporary global perspective. They are broadening the definition of what multiculturalism means to include to work on parallel cultural experiences in the context of global Internet communications. (Cope, Kalantzis and Ziguras 2003, 25)

Intercultural creative production occurs between artists of two or more linguistic and/or cultural backgrounds and, when successful, is often evident where collaborative processes are used to develop creative works. It is similar to cross-cultural production and has come into vogue with artists working in the multicultural space as a way of contemporising their creative practice. Intercultural does not necessarily require equality of creative input; however, in contemporary arts, it is often used to imply that all artists have some equality of creative input to effect a creative collaboration. This process is very challenging for artists more accustomed to their own practice. 
In discussing the influence of cultural diversity, performance artist Brian Fuata $(2011,22)$ describes the 'patchy and tentative' knowledge that led to his performances exploring his feminine role in Samoan society as a fa'a fafine:

It is a lived rather than known experience, a nickname, a family context, a child's drag act, someone else, a cultural ascription, a cyber friendship, a short film, a passing meeting, a google search, a wrong classification, an islander body. I know nothing more theoretical, official or definite.

Working collaboratively with other artists, Fuata works interculturally and, perhaps, trans-culturally-across cultural understandings and iconographies. This mode shows that artists have become more adept and less constrained in how they interact with each other's practices. According to Fuata $(2011,23)$, 'in relation to a notion of identity and the cultural diversity thereof, such a project reflects a contemporary arts society that is inherently diversified and acknowledging of that'. This artist is making a group effort with one artist at a time, and generating their own peer support network in the process of their practice. The scope of culturally diverse forms is, therefore, vast-definitely not a ghettoand continues to morph as artists seek out the new while grounding their work in something they find familiar.

I argue that the potential for creative practices emerging from Australia's multicultural society has yet to be fully realised or supported to the extent it warrants. Further, there is an expectation that NESB artists have a particular role and capacity to stimulate social transformation, in part through the scope of their practices if they can work interculturally.

\section{Conclusion}

This historical and sociological overview of the fields that inform multicultural arts has considered the conditions that support the practices of NESB artists. The similarity of critical and government discourse between the UK and Australia about diversity is clear; however, the UK has gone further to implement tied funding to achieve diversity outcomes. The British Government has positioned diversity in a critical role to generate a flourishing culture and, through ACE, is rewarding those companies that demonstrate their capability to deliver that role. The CCA is also investing in programs to stimulate that progress. 
By contrast, in Australia, the history of targeted funds from the 1970s onwards has witnessed bitter disagreements among art boards that have been expected to support the artistic work of migrants. These periods of friction have led to short productive phases of traction and change for the arts in a multicultural Australia. Key productive moments have occurred in 1982-86, 1993-96 and 2000-05, and are associated with articulate and politically astute ACMAC leadership, members and staff who recognise the importance of critical debate about multicultural issues within the arts.

The structural quandary of where migrant, ethnic, multicultural arts or AMA policy should be located at the Australia Council underlines the issue of a lack of trust in the art that has been produced by so-called ethnic artists. Their work has been labelled as 'amateur', has been associated with cultural maintenance and has been seen as being in direct opposition to artform codes of 'excellence'. Their role, as designated by the Australia Council, was to uphold traditional arts and crafts, which in turn raised questions regarding their capacity to be artists with contemporary practices. This higher moral ground about the suitability of the label 'contemporary' is mainly applied to ethnic artists.

That the majority of the Australia Council's funds support the performance of European classical 'heritage' arts (Blonski 1994, 199) is an irony that seems to have escaped the council's notice. Indigenous arts are supported for cultural maintenance as well as contemporary arts reasons. The history of multicultural arts practices highlights a range of tensions around issues of trust and leadership in terms of eligible creative endeavours and questionable aesthetic assumptions on the part of some decision-makers at the Australia Council. 
This text is taken from Creative Frictions: Arts Leadership, Policy and Practice in Multicultural Australia, by Cecelia Cmielewski, published 2021 by ANU Press, The Australian National University, Canberra, Australia.

doi.org/10.22459/CF.2021.01 